\title{
Composite method of design for heavily loaded wall-beam structures
}

\author{
J. R. RIDDINGTON \& B. STAFFORD SMITH
}

\section{Mr J. D. Peacock, Bison Concrete (Southern) Ltd}

I have been concerned with many schemes, but too few contracts, where composite construction has been proposed for use on housing sites where piles are deemed appropriate to overcome problems of ground heave. The requirement has been to leave voids below the pile beams and slabs, and this has naturally led to the consideration of a precast system.

44. For reasons of economy a pretensioned design for the beams and slabs is attractive, but $I$ have been discouraged by a prevailing attitude among local authority engineers and their consultants, who object to the proposals on the following grounds:

(a) none of the available publications, as far as I know, considers the use of prestressed beams, and the conclusion is that they may be unsatisfactory, although I have not yet heard any logical reason why this should be so, particularly since prestressed plank lintels have been used for many years;

(b) there are doubts regarding the ability to transfer inclined thrusts through a damp-proof course because of the possibility of reduced friction.

45. The latter point seems to have more validity and I should be grateful if the Authors could comment on the possible use of prestressed beams and any experience they may have had with suitable materials for damp-proof courses when a composite design is used.

46. I would also question the risk of tension cracking in the brickwork at the top of the wall over the supports, and wonder if the Authors have recognized this unwelcome possibility.

\section{Drs Riddington and Stafford Smith}

Mr Peacock's proposal for using the composite action between building walls and pile beams as an aid in spanning between piles appears to the Authors a most appropriate application of the structural principle. Although the presented design method was developed initially for walls on encased steel beams, the second Author has continued experimental research at McGill University sufficient to show that the principle-and presumably the method, with certain modifications-is equally appropriate to walls on reinforced concrete beams. The Authors cannot foresee any reason why prestressed concrete beams, with elastic properties better than those of reinforced concrete beams, should not be entirely suitable to work compositely with a masonry wall.

48. Where a damp-proof course is incorporated within a wall, composite action can be relied upon only if the material can transmit the considerable shear stress and increased compressive stresses that develop near the supports. Bitumen damp-proof 


\section{DISCUSSION}

courses, for example, would be quite unacceptable because of their tendency to creep and release the arching action. However, damp-proof courses of engineering brick, or made by impregnation of the masonry, should be acceptable, although the Authors do not have any direct experience of their use.

49. The Authors are well aware of cases of tension cracking at the top of continuous walls over supports, usually accompanied by tension cracking at mid-span at the bottom. Such cracking was due to the 'supporting' beam or slab sagging away from the wall due to creep and shrinkage. Certain early lightweight concrete slab systems were very prone to this problem. These observed walls were, however, usually of a low depth-to-span ratio of approximately 0.3 and had been behaving more as deep beams than arches.

50. In their design method the Authors recommended that a minimum restriction of 0.6 be placed on the depth-to-span ratio. Although this restriction was imposed to avoid spreading of the arch, it should serve also to prevent the beam type cracking described by Mr Peacock. 